\title{
The dynamic effects of shocks to labour markets: evidence from OECD countries
}

\author{
By Manuel Balmaseda ${ }^{\star}$, Juan J. Dolado $†$, and J. David López-Salidoł \\ ${ }^{\star}$ Research Department, Banco BBV \\ $\dagger$ Department of Economics, Universidad Carlos III, c/Madrid 126, 28903 Getafe, \\ Madrid, Spain; e-mail: dolado@eco.uc3m.es \\ $\ddagger$ Research Department, Banco de España
}

\begin{abstract}
This paper uses a set of plausible long-run identifying restrictions on a three-variable system, including output growth, real wage growth, and the unemployment rate, to isolate three independent structural shocks which drive fluctuations in those variables in a sample of 16 OECD countries during 1950-96. These shocks are interpreted as aggregate demand, productivity, and labour supply disturbances. As a by-product of the previous analysis, the cyclical behaviour of real wages in response to a demand shock is re-examined and two indices of real wage rigidity are derived.
\end{abstract}

\section{Introduction}

In this paper, we follow the so-called Structural Vector Autoregression approach (SVAR, henceforth), along the lines developed by Blanchard and Quah (1989), by making use of a set of long-run restrictions in a VAR in order to interpret reduced form innovations as structural shocks stemming from different sources. In this manner, we will be able to study the consequences of a particular shock on the variables forming the VAR. In particular, we want to focus on the role played by various shocks in explaining the joint dynamic behaviour of three key variables in the modelling of labour markets, namely, real output, real wages and the unemployment rate. Indeed, given that we have three variables in the system, we will then be able to identify three structural shocks that are labelled as aggregate demand, productivity, and labour supply shocks, respectively. This distinction seems useful since those shocks have been traditionally invoked as important factors in explaining the wide variety of labour market outcomes observed across OECD economics in the post-war period. Hence, through the identification of those shocks we will be able to analyse their contribution to labour market fluctuations in those countries, highlighting both the common and differential features across them.

As is well known, Blanchard and Quah (1989) analysed the dynamic correlations of real output growth and the unemployment rate in the US and were able to identify the effects of aggregate demand and supply shocks by making use of the standard neutrality restriction whereby demand shocks do not affect the level of output in the long-run. Later, several studies have extended the number of shocks 
in the system by enlarging the size of the VAR. ${ }^{1}$ Specifically, a precursor of the approach taken here is the study by Gamber and Joutz (1993) (GJ, henceforth) who disentangle supply shocks into two further shocks with a similar interpretation to the one offered in this paper. Nonetheless, our results generalise theirs in several directions.

First, we provide a simple supply-side model to explain the chosen identification outline which differes from GJ's arguments. According to GJ, the restriction that demand shocks have no long-run impact on the level of real wages is explained in terms of a Solow growth model with fixed saving rate. Rather than invoking the Solow model, we obtain the same set of restrictions by assuming that wages are set in an insider-outsider bargaining framework $a$ la Blanchard and Summers (1986), which is a more natural assumption when studying the functioning of labour markets in the OECD. As will become clear below, our modelling strategy has the advantage of not only encompassing GJ's identification scheme when unemployment is a stationary variable but also of nesting the case where unemployment has a unit root, a feature which seemingly characterises the high unemployment persistence in some European countries.

Second, we extend the analysis of shocks in the US economy undertaken by Blanchard and Quah (1989), and later by GJ, to a pool of OECD economies with reasonably long annual time series for real wages, real output and unemployment. This extension will permit us to examine whether the stylised facts found for the US also hold for other OECD countries.

Thirdly, as pointed out in GJ's study, identifying aggregate demand shocks is convenient for analysing another relevant issue in the behaviour of labour markets, namely, which is the cyclical pattern of real wages. The usual approach to measuring that cyclical behaviour is to regress the growth of real wages on some proxy for business-cycle fluctuations, such as real output growth. The problem with this approach is that demand and supply-induced shocks are expected to lead to opposite movements in the real wage. To the extent that business-cycle fluctuations are produced by both types of shock, it makes little sense to talk about procyclical or countercyclical real wages, since the cycle itself is a conglomeration of both shocks. Thus, following our approach, we will be able to characterise unambiguously the response of real wages to a demand shock and, in this manner, proceed to evaluate whether sticky wage theories or other alternative theories are more appropriate to describe real wage behaviour in our sample of countries.

Finally, a further advantage of the approach proposed here is that it allows us to compute an index of real wage rigidity which differs from the one so far available in the literature. The traditional index is based on the reciprocal of the estimated response of real wages to unemployment in wage equations which further control

\footnotetext{
${ }^{1}$ See, inter alia, Bean (1992), Gamber and Joutz (1993), Dolado and López-Salido (1996), Galí (1996), Dolado and Jimeno (1997), and Castillo et al. (1998).
} 
for a set of wage-pressure variables, such as bargaining structure, unemployment benefits, mismatch indices, and so on (see Layard, et al., 1991; LNJ, henceforth). The problem with this approach is that measurement problems in the construction of the wage-shift factors and dubious identification restrictions abound (see Manning, 1993). To overcome these difficulties, we use the SVAR approach to construct two alternative real wage rigidity indices which are then compared to the index reported by LNJ. Hence, in this sense, our approach will allow us to gauge how robust the available real wage rigidity rankings are under the competing SVAR methodology, where many of the suspicious variables are modelled in terms of shocks and the identification restrictions become clearer from the outset.

The rest of the paper is structured as follows. In Section 2 we present a simplified labour market model which helps to interpret the nature of the structural shocks driving economic fluctuations and next we discuss the implementation of the SVAR methodology. Section 3, in turn, describes the data and presents the results in terms of the usual tools in this kind of approach, namely, impulse-response functions and forecast error variance decompositions. Section 4 deals with the construction of two indices of real wage rigidity based on that type of methodology. Finally, Section 5 draws some concluding remarks.

\section{A stylised model to interpret shocks}

\subsection{A hysteretic framework}

To help interpret the structural shocks driving labour market fluctuations in the OECD, we start by presenting a simplified model which proves useful for the purpose at hand. Since our primary concern is to analyse issues related to labor market behaviour, such as the cyclical properties of real wages or unemployment hysteresis, our aim will be to identify three types of shock which we will denote as aggregate demand, productivity, and labor-supply shocks, respectively.

The model is fairly stylised and consists of five equations. The first three equations are as follows

$$
\begin{aligned}
& y=\varnothing(d-p)+a \theta \\
& y=n+\theta \\
& p=w-\theta
\end{aligned}
$$

where $y, p, n, w$, and $(d-p)$ denote the logs of real output, price level, employment, nominal wages and real aggregrate demand; $\theta$ and $d$, in turn, represent shift factors in productivity (technical progress and capital accumulation) and nominal expenditure (reflecting fiscal and monetary policies), respectively.

Equation (1) is a implified version of an aggregate demand function where $\varnothing>0$. Notice that productivity is allowed to affect aggregate demand through investment or consumption decisions (e.g., through permanent-income effects) so that $a>0$. Equation (2) is a (long-run) production function under a constant 
returns-to-scale (CRS) technology. Finally, eq. (3) describes the corresponding price-setting rule as a function of nominal wages and productivity. ${ }^{2}$

To characterise further the supply-side of the labor market the following equations are added to the model

$$
\begin{aligned}
l & =\alpha(w-p)-b u+\tau \\
w & =\arg \left\{n^{e}=\lambda l_{-1}+(1-\lambda) n_{-1}\right\}
\end{aligned}
$$

where $l$ is the $\log$ of the labor force, $n^{e}$ is the expected value of (log) employment, $u$ is the unemployment rate, and $\tau$ is a labor-supply shift factor. Finally, the definition of the unemployment rate implies

$$
u=l-n
$$

Equation (4) is a labor-supply function which depends upon real wages $(w-p)$ and the unemployment rate $(u)$. As regards the latter, we expect $b>0$ if the discouragement effect, whereby long-term unemployed get demoralized and withdraw from the labour force, dominates the offsetting effect, whereby if the head of household loses her job other secondary household members participate more; otherwise $b \leq 0 .^{3}$ Equation (5), in turn, characterizes the wage-setting behaviour. As in Blanchard and Summers (1986), targeted nominal wages are chosen one period in advance, and are set so as to equate expected employment to a weighted average of lagged labour supply and employment.

As is well known, the microfoundations of (5) follow typically from an insideroutsider framework which fits well with the characteristics of many labour markets, particularly those in Europe. This parameterization leads to partial-hysteresis when $0<\lambda<1$, and to full-hysteresis when $\lambda=0$.

To close the model, as customary, we need to specify the stochastic processes governing the evolution of the exogenous shift factors defined earlier. For illustrative purposes, we consider that $d, \theta$, and $\tau$ evolve as simply random walks. ${ }^{4}$

$$
\begin{aligned}
\Delta d & =\varepsilon_{d} \\
\Delta \theta & =\varepsilon_{s} \\
\Delta \tau & =\varepsilon_{l}
\end{aligned}
$$

where $\varepsilon_{d}, \varepsilon_{s}$, and $\varepsilon_{l}$ are uncorrelated i.i.d. aggregate demand, productivity and labor-supply shocks, governing the evolution of $d, \theta$, and $\tau$, respectively.

Solving eqs (1)-(9) for real wages, real output and unemployment yields

$$
\Delta(w-p)=\varepsilon_{s}
$$

\footnotetext{
${ }^{2}$ Equations (1) to (3) are similar to those found in Blanchard and Quah (1989).

${ }^{3}$ Nickell (1987), Lindbeck and Snower (1988) and Blanchard (1991) have provided theoretical arguments that justify how this outsider mechanism can lead to additional persistence and thus to a smaller discipline effect of unemployment on wages.

${ }^{4}$ The random walk hypothesis is just adopted to simplify the subsequent algebra. In general, we just need to assume that the exogenous shift factors are I(1) processes.
} 


$$
\begin{aligned}
(1-\rho L) \Delta y= & \varnothing \Delta \varepsilon_{d}+[\varnothing+a-(1+c)(1-\rho)] \Delta \varepsilon_{s}-(1-\rho) \Delta \varepsilon_{1} \\
& +(1+\alpha)(1-\rho) \varepsilon_{s}+(1-\rho) \varepsilon_{l} \\
(1-\rho L) u= & (1+b)^{-1}\left[(1+\alpha-\phi-a) \varepsilon_{s}-\phi \varepsilon_{d}+\varepsilon_{l}\right]
\end{aligned}
$$

where $L$ is the lag operator, $\Delta \equiv 1-L$ and $\rho=(1+b)^{-1}(1+b-\lambda)$. Thus, in this partial-hysteresis framework, the persistence of unemployment is an increasing function of both the discouragement effect $(b)$ and the influence of lagged employment on wage determination $(\lambda)$. Note that, for finite $b, \rho=1$ is equivalent to $\lambda=0$, so that full-hysteresis is equivalent to the unemployment rate being an I(1) variable, whereas real wages and output will remain $\mathrm{I}(1)$ processes in both cases.

To highlight the long-run identifying restrictions embedded in eqs. (10)-(12), let us omit the dating of variables and shocks and write the matrix of long-run multipliers of the system in the following more compact form

$$
\left(\begin{array}{c}
\Delta(w-p) \\
\Delta y \\
u
\end{array}\right)=\left(\begin{array}{ccc}
c_{11}(1) & 0 & 0 \\
c_{21}(1) & c_{22}(1) & 0 \\
c_{31}(1) & c_{32}(1) & c_{33}(1)
\end{array}\right)\left(\begin{array}{c}
\varepsilon_{s} \\
\varepsilon_{l} \\
\varepsilon_{d}
\end{array}\right)
$$

where $c_{11}(1)=1, \quad c_{21}(1)=(1+\alpha), \quad c_{22}(1)=1, \quad c_{31}(1)=D^{-1}(1+\alpha-\varnothing-a)$; $c_{32}(1)=D^{-1}$ and $c_{33}(1)=-\varnothing D^{-1}$ with $D=(1+b)(1-\rho)$.

From eq. (13) we observe that demand shocks are restricted to have no permanent effects on both the levels of real output and real wages. As will become clear below, both restrictions are concomitant to the natural rate hypothesis, i.e., that $u$ is an $\mathrm{I}(0)$ process. Finally, the identification of labour-supply shocks is based upon the assumption that real wages are only driven in the long-run by productivity shocks, a hypothesis which stems from the CRS assumption in the production function. In fact, all these restrictions are identical to the ones imposed by GJ but derived from different arguments, as discussed above.

Notice that under our interpretation of the identification scheme, the possibility of allowing for full-hysteresis is envisaged. This assumption implies that the wagesetting eq. (5) now becomes $w=\arg \left\{n^{e}=n_{-1}\right\}$, yielding the following matrix of long-run multipliers

$$
\left(\begin{array}{c}
\Delta(w-p) \\
\Delta y \\
\Delta u
\end{array}\right)=\left(\begin{array}{ccc}
c_{11}(1) & 0 & 0 \\
c_{21}(1) & c_{22}(1) & 0 \\
c_{31}(1) & c_{32}(1) & c_{33}(1)
\end{array}\right)\left(\begin{array}{c}
\varepsilon_{s} \\
\varepsilon_{d} \\
\varepsilon_{l}
\end{array}\right)
$$

where now $c_{11}(1)=1, c_{21}(1)=\varnothing+a, c_{22}(1)=\varnothing, c_{31}(1)=D^{-1}(1+\alpha-\varnothing-a)$; $c_{32}(1)=-D^{-1} \varnothing$ and $c_{33}(1)=D^{-1}$, with $D=(1+b)$. Thus, by allowing for the possibility of full-hysteresis, i.e., $\lambda=0$, we obtain a similar recursive identification scheme to that obtained in the partial-hysteresis case, but which some distinctive features. First, the unemployment rate is an $\mathrm{I}(1)$ process rather than $\mathrm{I}(0)$. And, second, there is a switch in the role of aggregate demand and labor-supply shocks as regards their permanent effect on real output. Whereas, under partial-hysteresis, aggregate demand shocks do not affect the level of output in the long-run, under full-hysteresis labour supply shocks are the shocks with no long-run effect on 
output. Naturally, the stochastic properties of the unemployment rate, i.e., whether it is an $\mathrm{I}(1)$ or an $\mathrm{I}(0)$ variable, will be crucial in choosing the appropriate identification scheme.

Lastly, before describing the implementation of the SVAR methodology under the chosen set of long-run identifying restrictions, it seems convenient to discuss briefly how various well-known shocks—such as those arising from oil prices, labour taxes, unemployment benefits, and union power-can be addressed within our framework. Since the variables underlying these shocks have been instrumental in explaining the different paths of unemployment in OECD countries in previous studies (see LNJ, 1991), it seems paramount to explain how they fit in. As regards oil price shocks, the easiest way to interpret them is as negative productivity shocks $\left(\varepsilon_{s}\right)$ which increase (decrease) price-wage margins (real wage) while raising unemployment if the following inequality holds: $\phi+a>1+\alpha$. With regard to the remaining shocks, they can all be considered as wage-push shocks, giving rise to two alternative interpretations. Firstly, given that the price-setting rule is horizontal in the real wage-unemployment space, those shocks will not change real wages in the long-run whilst they will increase unemployment; thus, the easiest way to interpret them is as positive labour supply shocks $\left(\varepsilon_{l}\right)$ (see eq. (12)). For example, more generous benefits or stronger union power, can be thought of as encouraging labour market participation, i.e. an increase in $\tau$. Secondly, higher labour taxes could affect capital accumulation and so unemployment through negative productivity shocks, assuming again that the inequality $\phi+a>1+\alpha$, holds.

\subsection{VAR identification}

In order to identify the three shocks defined above, we consider the following VAR model

$$
A(L) X_{t}=\mu_{t}+\eta_{t}
$$

where $X_{t}$ is a $(3 \times 1)$ vector of variables including $\left[\Delta(w-p)_{t}, \Delta y_{t}, u_{t}\right]$ in the partial-hysteresis version of the model and $\left[(\Delta w-p)_{t}, \Delta y_{t}, \Delta u_{t}\right]$ in the fullhysteresis one; $A(L)$ is a $k$-th order matrix of lag polynomials in the lag operator $L$ with all its roots outside the unit circle and $A(0)=I ; \mu_{t}$ is a vector of deterministic terms-including, say, a constant-and $\eta_{t}$ is a vector of zero-mean i.i.d. innovations with covariance matrix $\Sigma$. The Wold moving-average representation of (14) is given by

$$
X_{t}=D(L) \eta_{t}
$$

where $D(L)=A(L)^{-1}, D_{0}=I$, and the deterministic terms have been omitted for simplicity. The innovations are expressed as linear combinations of the shocks, i.e., $\eta=S \varepsilon_{t}$, where $S$ is a $(3 \times 3)$ mapping matrix. Assuming that the $\varepsilon_{t}$ 's are uncorrelated i.i.d. shocks with unit variances, since they are of different sources, we get the following structural moving-average representation

$$
X_{t}=C(L) \varepsilon_{t}
$$


where $C(L)=D(L) S, C_{0}=S$. To identify the nine elements in $S$, three restrictions are needed given that the orthonormality of $\varepsilon_{t}$ already imposes six restrictions stemming from the different elements of the covariance matrix $\Sigma$. Those required restrictions can be easily obtained from the structure of $S$ in expressions (13) and $\left(13^{\prime}\right)$, by exploiting the absence of long-run impact of some shocks on some of the variables. As Clarida and Galí (1994) have shown, assuming that the matrix of long-run multipliers, $C(1)$, is lower triangular (as is the case in our theoretical models), $S$ can be easily obtained as

$$
S=D(1)^{-1} \tilde{C}
$$

where $\tilde{C}$ is the unique Cholesky lower triangular factor of the matrix $D(1) \Sigma D(1)^{\prime}$ which can be easily estimated from the VAR in (14).

\section{Implementation and results}

\subsection{Data}

The data are from the Centre of Economic Performance (CEP/LSE) data base updated to 1996. We use annual data on the real gross domestic product, real labour costs in terms of the GDP deflator and the OECD standardized unemployment rate. We chose a subset of 16 countries for which there is a long continuous set of observations in the three variables during the post-war period. These countries and the years of data available are listed in Table 1; in general, the sample runs from 1950 to 1996.

\subsection{Unit root tests on unemployment}

As explained above, to test whether specification $\left(13^{\prime}\right)$ is more appropriate than (13) we simply need to test whether unemployment is $\mathrm{I}(1)$. To do this, rather than simply carrying out the standard battery of univariate unit root tests on $u$, which usually do not reject that $u$ is $\mathrm{I}(1)$ in most countries due to lack of power, we test for such a null hypothesis in multivariate framework using Johansen's (1995) cointegration approach, which has larger power due to the use

Table 1 Data description

\begin{tabular}{llll}
\hline Country & Sample & Country & Sample \\
\hline Australia & $1950-96$ & Italy & $1954-96$ \\
Austria & $1950-96$ & Japan & $1952-96$ \\
Belgium & $1950-96$ & Netherlands & $1950-96$ \\
Canada & $1950-96$ & Norway & $1952-96$ \\
Denmark & $1950-96$ & Spain & $1954-96$ \\
France & $1950-96$ & Sweden & $1950-96$ \\
Germany & $1950-96$ & U.K. & $1950-96$ \\
Ireland & $1950-96$ & U.S. & $1950-96$ \\
\hline
\end{tabular}

Note: Sample refers to years of data. 
Table 2 Unit root tests for unemployment (Johansen's Trace Test).

\begin{tabular}{lccc}
\hline Country & $\boldsymbol{H}_{\mathbf{0}}: \boldsymbol{r}=\mathbf{0}^{*}$ & $\boldsymbol{H}_{\mathbf{0}}^{\prime}: \boldsymbol{r}=\mathbf{1 \dagger}$ & $\boldsymbol{H}_{\mathbf{0}}^{\prime \prime}: \boldsymbol{\beta}=[\mathbf{0}, \mathbf{0}, \mathbf{1}] \boldsymbol{\dagger}$ \\
\hline Australia & 42.6 & 16.2 & 5.2 \\
Austria & 40.3 & 13.4 & 4.6 \\
Belgium & 38.6 & 17.1 & 3.2 \\
Canada & 35.6 & 16.0 & 6.1 \\
Denmark & 39.3 & 17.7 & 5.3 \\
France & 36.3 & 15.3 & 4.2 \\
Germany & 35.1 & 14.6 & 4.3 \\
Ireland & 37.6 & 18.2 & 5.9 \\
Italy & 36.4 & 16.4 & 5.8 \\
Japan & 43.5 & 12.2 & 2.3 \\
Netherlands & 38.6 & 15.4 & 4.6 \\
Norway & 43.2 & 13.6 & 4.9 \\
Spain & 31.2 & 20.2 & 7.3 \\
Sweden & 40.5 & 13.4 & 5.2 \\
U.K. & 36.8 & 16.2 & 5.5 \\
U.S. & 41.4 & 12.6 & 4.3 \\
CV (5\%) & 34.6 & 18.2 & 6.0 \\
\hline
\end{tabular}

Note: $\left({ }^{*}\right)$ denotes the null hypothesis that the cointegrating rank $(r)$ is equal to zero; $(\dagger)$ denotes the null hypothesis that the cointegrating rank $(r)$ is unity; $(\ddagger)$ denotes the null hypothesis that the cointegrating vector $(\beta)$ is $(0,0,1)^{\prime}$; critical values $(\mathrm{CV})$ are taken from Table 2 (case 2, Trace) in Osterwald-Lenum (1992).

of covariates. As is well known, if we have $n \mathrm{I}(1)$ variables, there can be at most $r \leq n-1$ cointegrating vectors. Thus, if we model a VAR in levels including $[(w-p), y, u]$, and an unrestricted linear trend, and we cannot reject both the null hypotheses that $r=1$, while $r=0$ is rejected, and that the cointegrating vector has the form $(0,0,1)$, this will mean that $u$ is $\mathrm{I}(0)$ while $(w-p)$ and $y$ are $\mathrm{I}(1)$ processes, without cointegration among the three variables. This will be in agreement with the partial-hysteresis specification of the VAR and will constitute the testing approach taken here.

Table 2 reports the results for the 16 countries. The 5\% critical values for $H_{0}: r=0$ and $H_{0}^{\prime}: r=1$ are taken from Osterwald-Lenum (1992) whereas the test for the null that the cointegrating vector is $(0,0,1)$ is distributed as $\chi^{2}(2)$ (see Johansen, 1995). For most countries, the hypothesis that $u$ is $\mathrm{I}(0)$ seems to be accepted, favouring the partial-hysteresis interpretation. Even for Spain, where unemployment has risen by almost 20 percentage points over the sample period and where a unit root cannot be rejected, assuming that the consequences of a shock will last for ever does not seem very satisfactory. Thus, in agreement with the partial hysteresis set-up, the analysis in the rest of the paper will be based on a VAR formed by $[\Delta(w-p), \Delta y, u]$, including a constant term. The lag length has been chosen on the basis of the SBIC criteria and the absence of serial correlation in the residuals has been tested with the Box-Ljung Q test. In all cases, a VAR with 2 lags proved to be a reasonable choice. 


\subsection{Impulse-response functions}

We begin with the discussion of the propagation of the shocks by means of the impulse-responses (IR) of the three variables in the VAR to the different shocks. Given the large number of IR functions, we choose to report those of four representative countries in the sample (France, Germany, UK, and US) which are displayed in Fig. 1. However, when necessary, we will also briefly extend the discussion to all countries in the sample. Solid lines depict point estimates of the response of the variables to a one-unit shock. Broken lines depict approximate $90 \%$ confidence intervals computed using 1,000 bootstrap replications according to the method proposed by Runkle (1987). In general, the response of real wages with respect to the three types of shock is fairly satisfactory. They increase both in the short- and the long-run in response to a (positive) productivity shock and decrease in the short-run in response to a (positive) labour-supply shock. In turn, the response of real wages with respect to (positive) aggregate demand shock tends to be countercyclical in the short-run, with the exception of the US where there are clear signs of pro-cyclical behaviour, confirming GJ's findings. Thus, the results obtained by GJ for the US do not extend to the rest of OECD countries in the sample. This may explain why Real Business Cycle theories, which stress the procyclical behaviour of real wages, have been most popular in the US whereas in other OECD economies, theories based upon sticky wages have been more prominent (see Fischer, 1977).

With respect to the responses of real output to the different shocks, we observe that it tends to react positively to both productivity and labour supply shocks at all frequencies, and to demand shocks in the short-run. Finally, as regards unemployment it tends to increase temporarily to a productivity shock, as in GJ's analysis. Likewise, unemployment increases in response to a labour supply shock whereas it decreases in response to a positive aggregate demand shock. The first effect, namely, the temporary increase in unemployment following a positive one-unit productivity shock seems to support the so-called 'technological bias' explanation of unemployment as a short-run phenomenon.

\subsection{Variance decompositions}

Next, we discuss the role played by each shock in explaining the variability of each variable in the system. Table 3 presents the forecast-error variance (FEV) decomposition of the three variables at various horizons representing the short-run (one year), medium-run (five years), and long-run (asymptotically) contributions of the shocks to the variance of the forecast errors of the variables in the VAR.

As regards real wages, productivity shocks account for over $50 \%$ of its variance in the short-run and near $100 \%$ in the long-run. Only in the case of Ireland, the other two shocks slightly dominate the FEV decomposition in the short-run but then they tend to lose importance later, gradually being replaced by productivity shocks, in agreement with the identifying restrictions imposed on the VAR. 

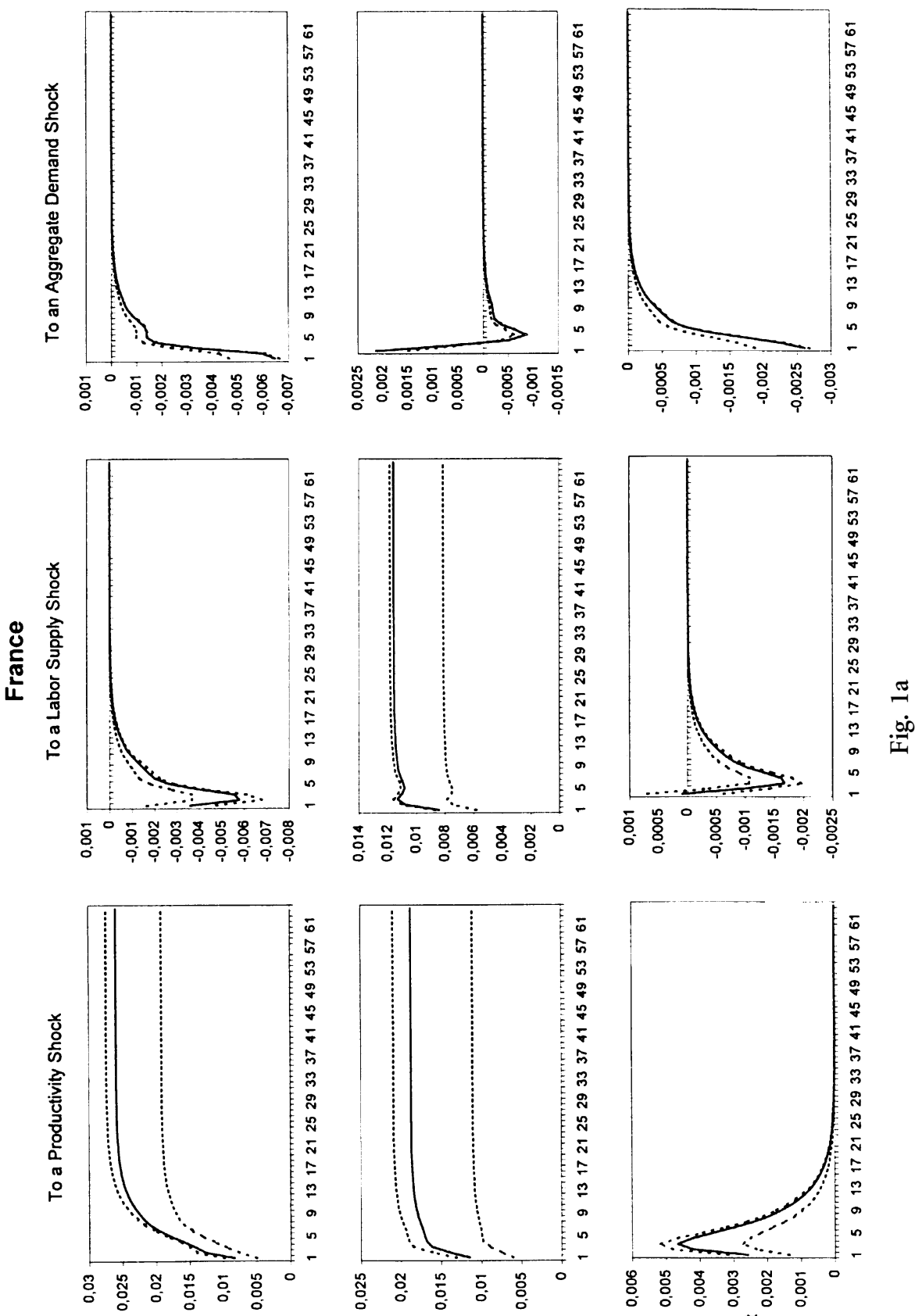

离

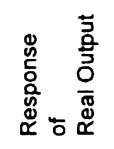

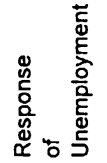


BALMASEDA $E T A L$.

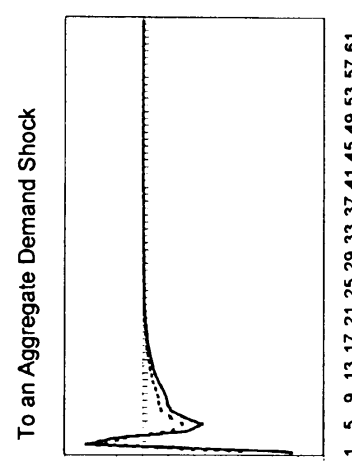

美
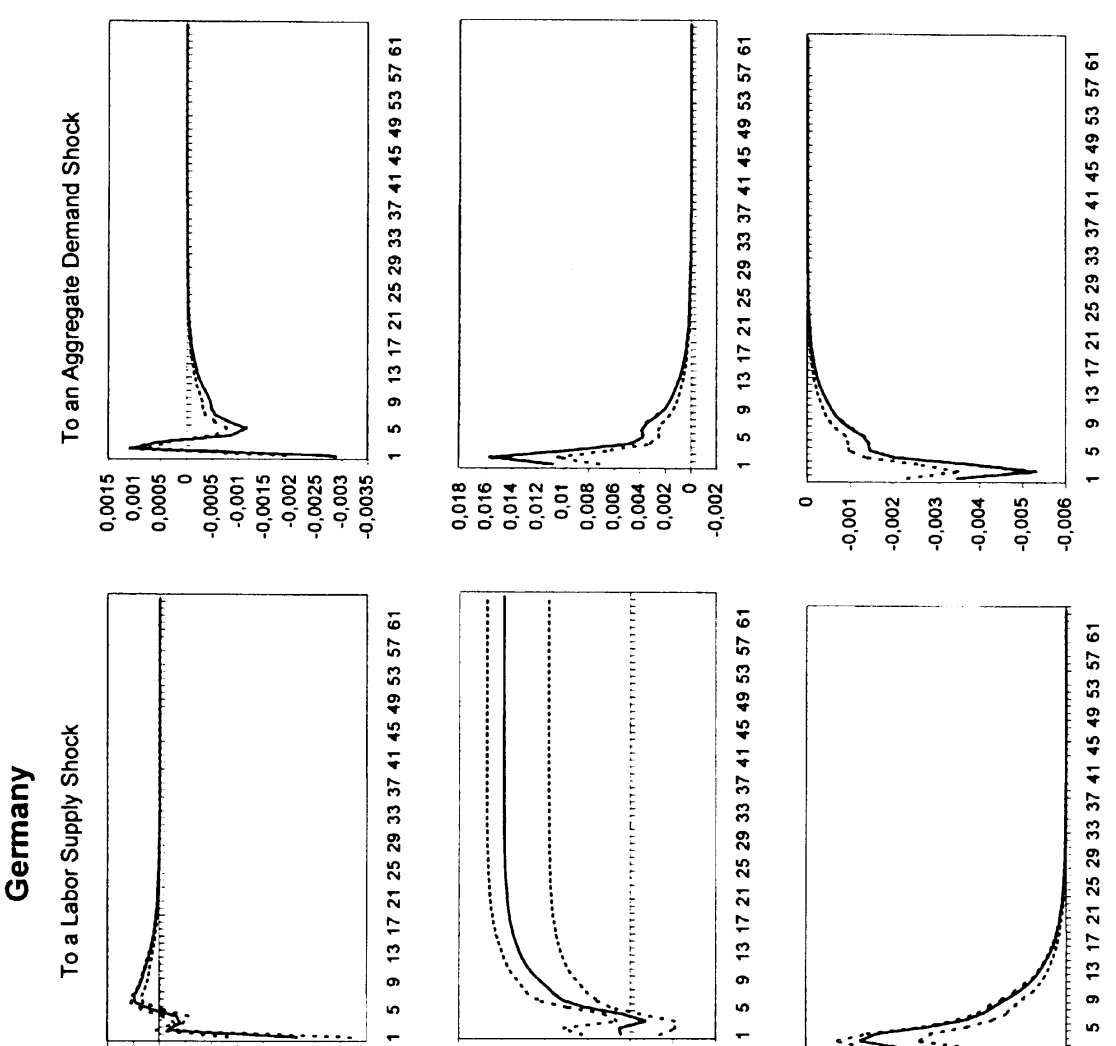

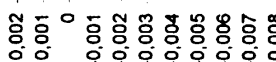
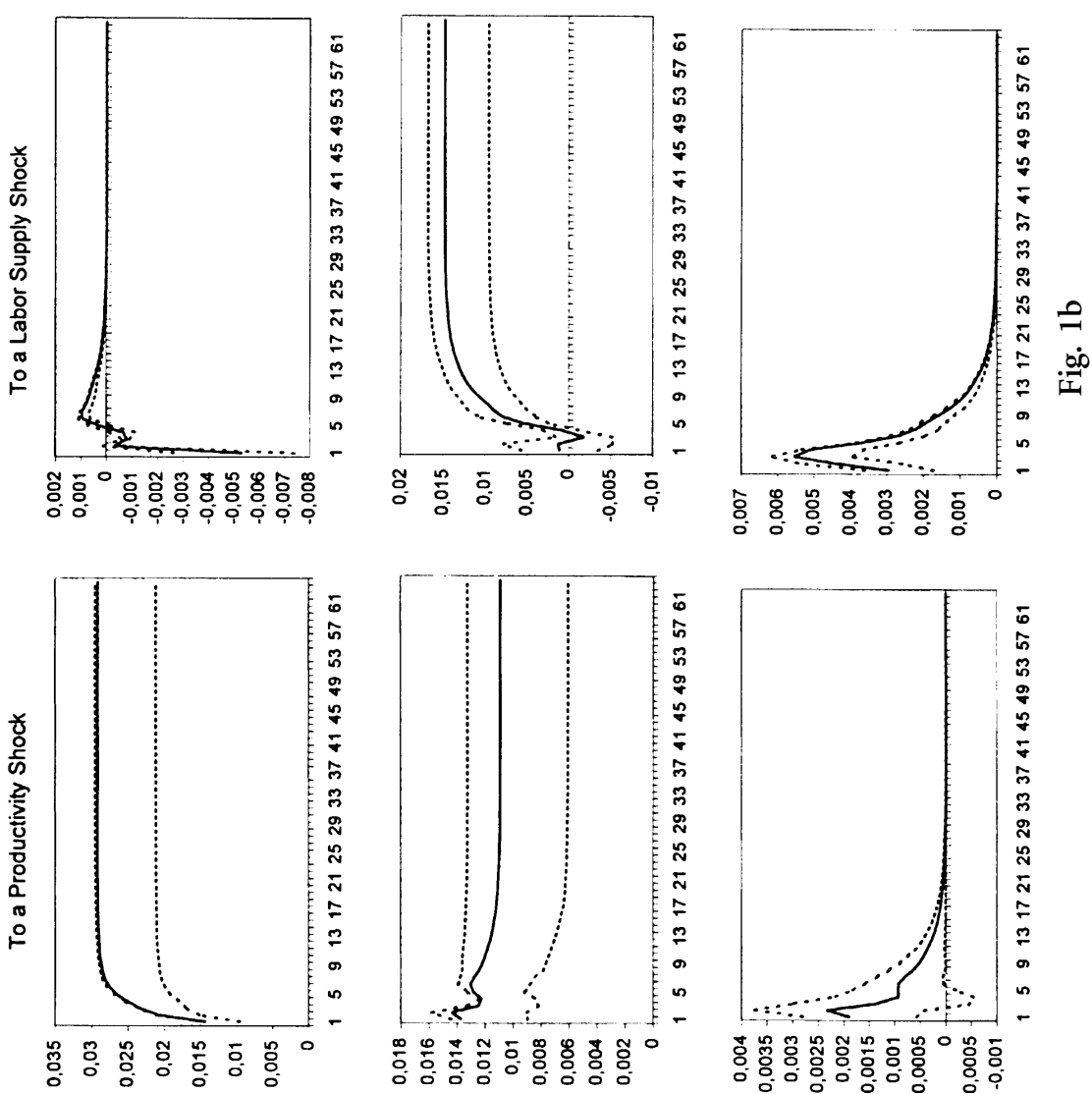

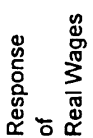
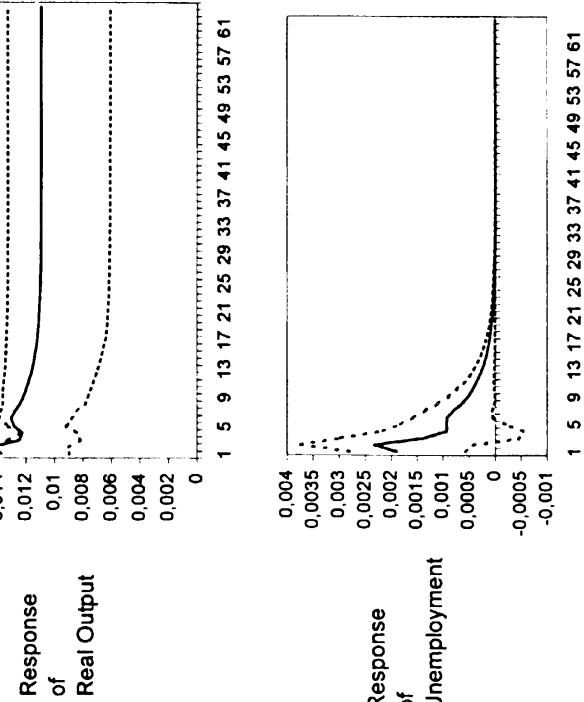

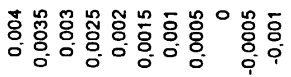

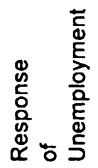




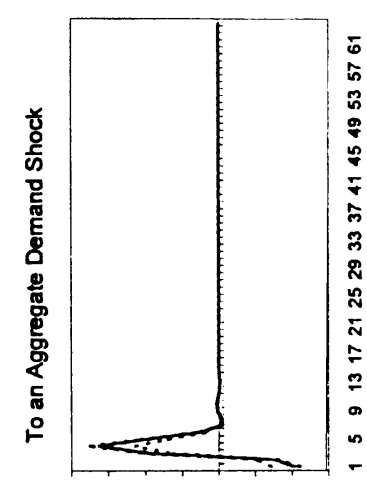

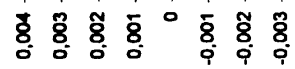

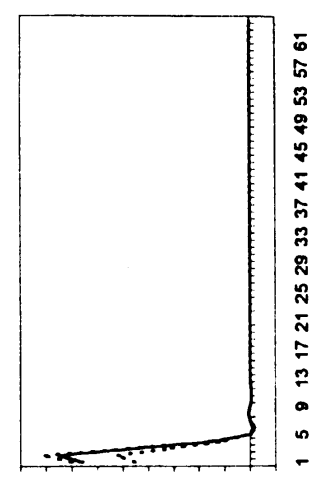

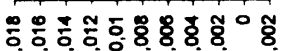
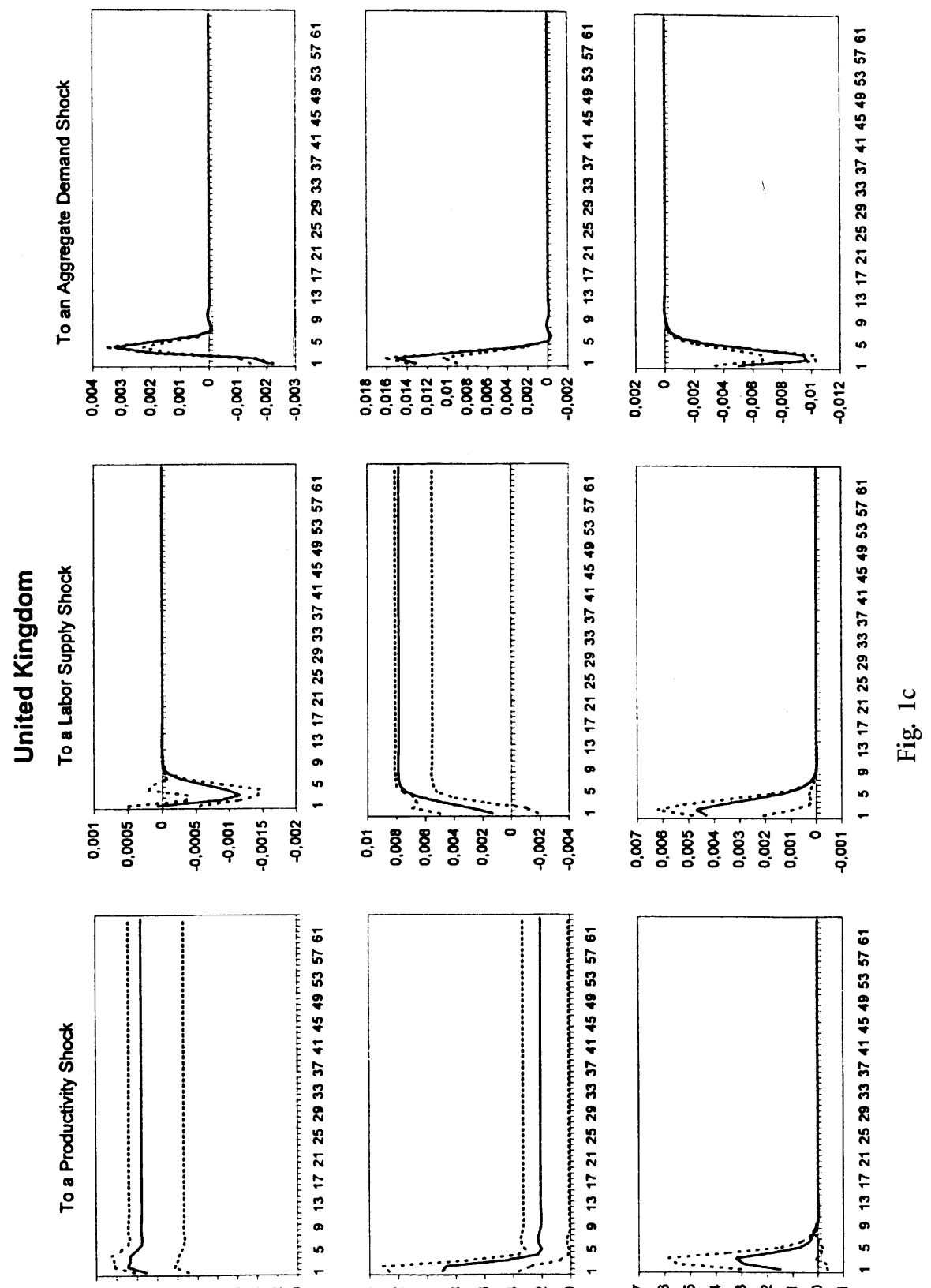

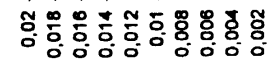

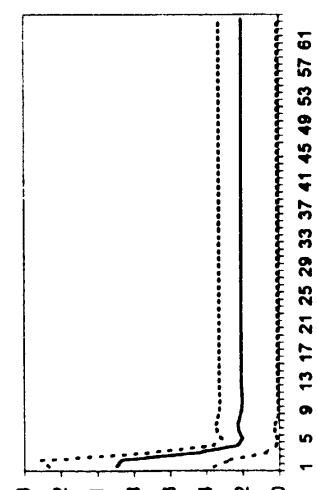

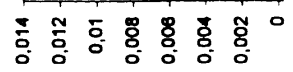
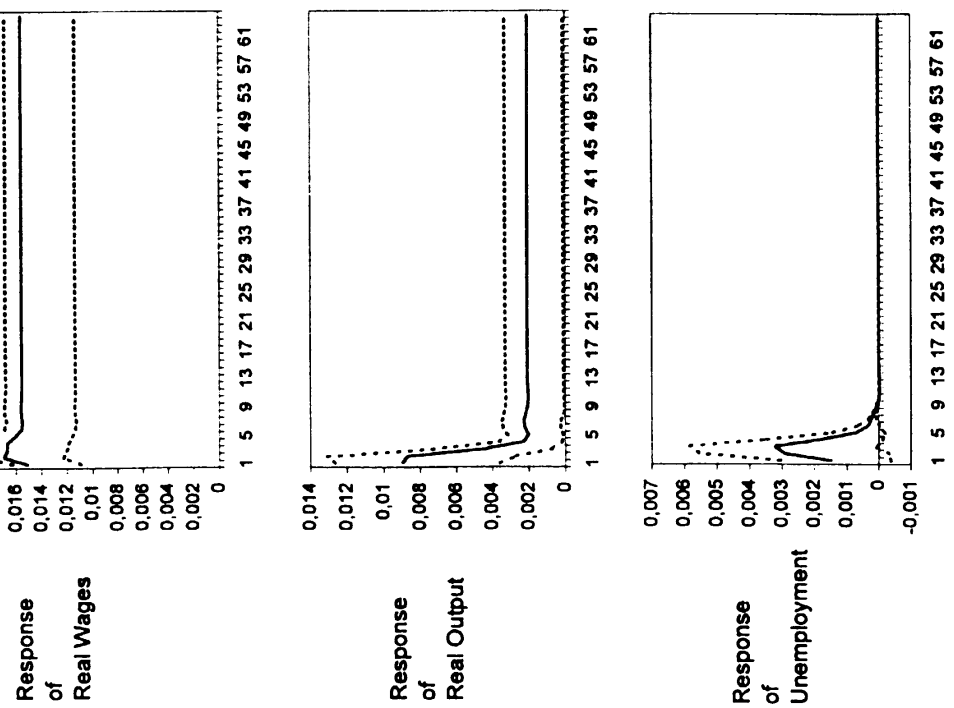

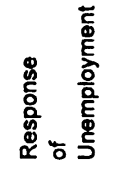




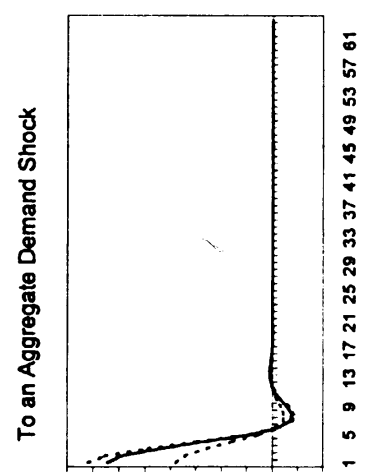

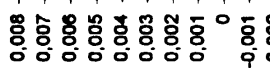
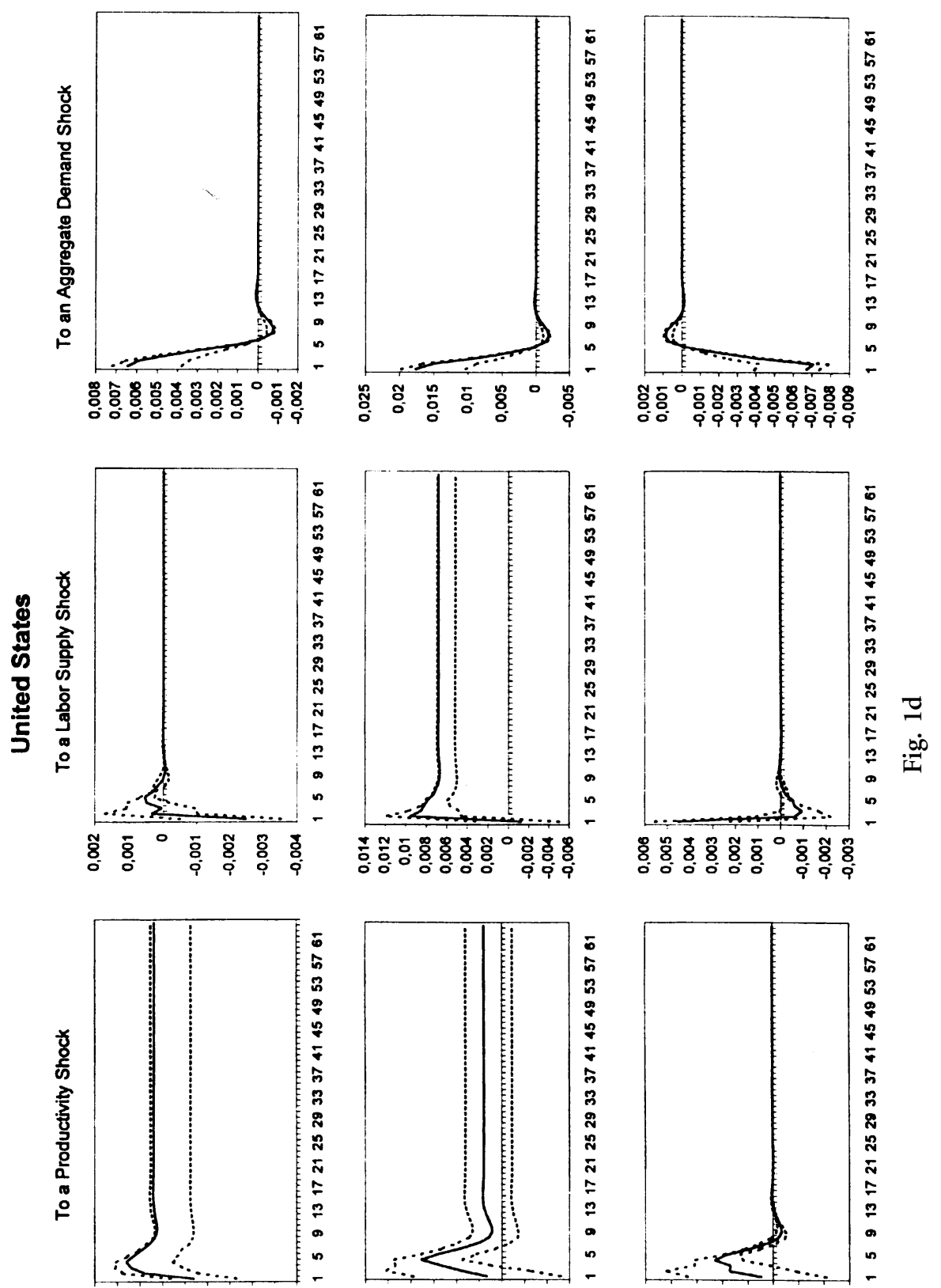

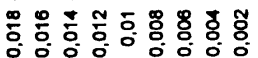
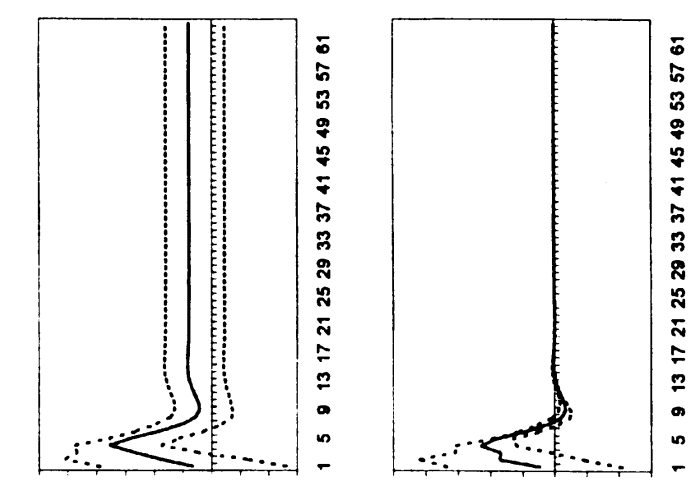

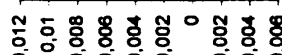

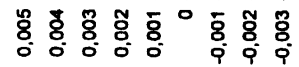

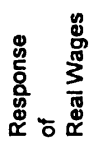

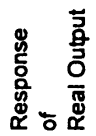

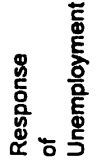


Table 3 Forecast error variance (FEV) decomposition.

\begin{tabular}{|c|c|c|c|c|c|}
\hline \multicolumn{2}{|c|}{ Country/variable } & \multirow{2}{*}{$\begin{array}{c}\text { Lag } \\
1\end{array}$} & \multirow{2}{*}{$\begin{array}{c}\varepsilon_{s} \\
85(7)\end{array}$} & \multirow{2}{*}{$\frac{\varepsilon_{l}}{5(3)}$} & \multirow{2}{*}{$\frac{\boldsymbol{\varepsilon}_{\boldsymbol{d}}}{10(5)}$} \\
\hline Australia & real wage & & & & \\
\hline & & 5 & $89(5)$ & $6(3)$ & $5(3)$ \\
\hline & & $\infty$ & $45(13)$ & $1(0)$ & $0(0)$ \\
\hline & output & 1 & $45(13)$ & $24(12)$ & $31(6)$ \\
\hline & & 5 & $62(12)$ & $23(11)$ & $15(3)$ \\
\hline & & $\infty$ & $63(12)$ & $37(13)$ & $0(0)$ \\
\hline & unemployment & 1 & $22(10)$ & $14(3)$ & $64(11)$ \\
\hline & & 5 & $36(10)$ & $12(9)$ & $45(10)$ \\
\hline & & $\infty$ & $42(11)$ & $24(9)$ & $34(8)$ \\
\hline \multirow[t]{9}{*}{ Austria } & real wage & 1 & $81(6)$ & $15(6)$ & $5(1)$ \\
\hline & & 5 & $95(2)$ & $5(2)$ & $0(0)$ \\
\hline & & $\infty$ & $100(0)$ & $0(0)$ & $0(0)$ \\
\hline & output & 1 & $76(10)$ & $9(8)$ & $15(8)$ \\
\hline & & 5 & $75(9)$ & $8(6)$ & $17(6)$ \\
\hline & & $\infty$ & $74(2)$ & $8(5)$ & $16(3)$ \\
\hline & unemployment & 1 & $27(10)$ & $44(12)$ & $29(11)$ \\
\hline & & 5 & $53(10)$ & $20(9)$ & $27(8)$ \\
\hline & & $\infty$ & $66(8)$ & $19(8)$ & $15(5)$ \\
\hline \multirow[t]{9}{*}{ Belgium } & real wage & 1 & $66(6)$ & $5(3)$ & $29(3)$ \\
\hline & & 5 & $93(1)$ & $0(0)$ & $7(1)$ \\
\hline & & $\infty$ & $100(0)$ & $0(0)$ & $0(0)$ \\
\hline & output & 1 & $75(6)$ & $5(2)$ & $20(3)$ \\
\hline & & 5 & $82(5)$ & $6(1)$ & $12(2)$ \\
\hline & & $\infty$ & $78(2)$ & $10(0)$ & $12(1)$ \\
\hline & unemployment & 1 & $56(7)$ & $3(2)$ & $41(5)$ \\
\hline & & 5 & $53(5)$ & $8(2)$ & $39(4)$ \\
\hline & & $\infty$ & $50(5)$ & $12(2)$ & $38(3)$ \\
\hline \multirow[t]{9}{*}{ Canada } & real wage & 1 & $59(9)$ & $0(2)$ & $41(8)$ \\
\hline & & 5 & $83(4)$ & $2(1)$ & $15(4)$ \\
\hline & & $\infty$ & $98(1)$ & $0(0)$ & $2(0)$ \\
\hline & output & 1 & $45(13)$ & $17(2)$ & $38(6)$ \\
\hline & & 5 & $69(13)$ & $14(1)$ & $17(4)$ \\
\hline & & $\infty$ & $76(11)$ & $11(1)$ & $13(3)$ \\
\hline & unemployment & 1 & $53(15)$ & $2(3)$ & $45(13)$ \\
\hline & & 5 & $47(12)$ & $12(7)$ & $41(11)$ \\
\hline & & $\infty$ & $53(12)$ & $14(7)$ & $33(10)$ \\
\hline \multirow[t]{9}{*}{ Denmark } & real wage & 1 & $53(17)$ & $12(4)$ & $35(15)$ \\
\hline & & 5 & $78(9)$ & $2(2)$ & $20(9)$ \\
\hline & & $\infty$ & $99(1)$ & $0(0)$ & $1(1)$ \\
\hline & output & 1 & $63(6)$ & $26(6)$ & $11(3)$ \\
\hline & & 5 & $80(5)$ & $19(5)$ & $1(0)$ \\
\hline & & $\infty$ & $84(4)$ & $15(4)$ & $1(0)$ \\
\hline & unemployment & 1 & $37(9)$ & $0(4)$ & $63(9)$ \\
\hline & & 5 & $55(8)$ & $5(3)$ & $40(8)$ \\
\hline & & $\infty$ & $62(8)$ & $4(3)$ & $34(7)$ \\
\hline
\end{tabular}


Table 3-(continued)

\begin{tabular}{|c|c|c|c|c|c|}
\hline \multicolumn{2}{|c|}{ Country/variable } & \multirow{2}{*}{$\frac{\text { Lag }}{1}$} & \multirow{2}{*}{$\begin{array}{c}\boldsymbol{\varepsilon}_{\boldsymbol{s}} \\
56(8)\end{array}$} & \multirow{2}{*}{$\frac{\boldsymbol{\varepsilon}_{\boldsymbol{l}}}{10(6)}$} & \multirow{2}{*}{$\frac{\boldsymbol{\varepsilon}_{\boldsymbol{d}}}{34(8)}$} \\
\hline France & real wage & & & & \\
\hline & & 5 & $84(3)$ & $8(3)$ & $8(2)$ \\
\hline & & $\infty$ & $99(0)$ & $0(0)$ & $1(0)$ \\
\hline & output & 1 & $64(10)$ & $24(10)$ & $12(1)$ \\
\hline & & 5 & $68(9)$ & $20(9)$ & $12(1)$ \\
\hline & & $\infty$ & $72(8)$ & $18(8)$ & $10(0)$ \\
\hline & unemployment & 1 & $49(12)$ & $0(2)$ & $31(13)$ \\
\hline & & 5 & $75(8)$ & $5(1)$ & $20(7)$ \\
\hline & & $\infty$ & $82(6)$ & $8(4)$ & $10(4)$ \\
\hline \multirow[t]{9}{*}{ Germany } & real wage & 1 & $75(7)$ & $12(6)$ & $13(2)$ \\
\hline & & 5 & $98(1)$ & $1(0)$ & $1(0)$ \\
\hline & & $\infty$ & $100(0)$ & $0(0)$ & $1(0)$ \\
\hline & output & 1 & $62(10)$ & $0(4)$ & $28(10)$ \\
\hline & & 5 & $63(92)$ & $13(4)$ & $24(7)$ \\
\hline & & $\infty$ & $60(13)$ & $22(3)$ & $18(3)$ \\
\hline & unemployment & 1 & $35(11)$ & $15(11)$ & $49(13)$ \\
\hline & & 5 & $54(10)$ & $18(9)$ & $28(10)$ \\
\hline & & $\infty$ & $64(9)$ & $15(9)$ & $21(7)$ \\
\hline \multirow[t]{9}{*}{ Ireland } & real wage & 1 & $25(10)$ & $35(11)$ & $40(3)$ \\
\hline & & 5 & $71(6)$ & $10(11)$ & $19(3)$ \\
\hline & & $\infty$ & $99(0)$ & $1(0)$ & $0(0)$ \\
\hline & output & 1 & $70(8)$ & $10(4)$ & $20(6)$ \\
\hline & & 5 & $75(40)$ & $21(3)$ & $4(1)$ \\
\hline & & $\infty$ & $79(41)$ & $21(3)$ & $0(0)$ \\
\hline & unemployment & 1 & $16(8)$ & $56(12)$ & $28(6)$ \\
\hline & & 5 & $19(8)$ & $59(7)$ & $22(5)$ \\
\hline & & $\infty$ & $33(6)$ & $50(7)$ & $17(4)$ \\
\hline \multirow[t]{9}{*}{ Italy } & real wage & 1 & $79(4)$ & $5(3)$ & $15(2)$ \\
\hline & & 5 & $97(1)$ & $2(0)$ & $1(0)$ \\
\hline & & $\infty$ & $100(0)$ & $0(0)$ & $0(0)$ \\
\hline & output & 1 & $53(12)$ & $33(8)$ & $31(3)$ \\
\hline & & 5 & $73(11)$ & $17(5)$ & $20(2)$ \\
\hline & & $\infty$ & $83(10)$ & $17(5)$ & $13(2)$ \\
\hline & unemployment & 1 & $20(9)$ & $12(6)$ & $68(8)$ \\
\hline & & 5 & $42(5)$ & $8(5)$ & $50(10)$ \\
\hline & & $\infty$ & $43(5)$ & $14(5)$ & $43(10)$ \\
\hline \multirow[t]{9}{*}{ Japan } & real wage & 1 & $65(9)$ & $24(9)$ & $11(1)$ \\
\hline & & 5 & 87 (2) & $12(5)$ & $1(0)$ \\
\hline & & $\infty$ & $99(0)$ & $1(0)$ & $0(0)$ \\
\hline & output & 1 & $73(11)$ & $11(6)$ & $16(7)$ \\
\hline & & 5 & $78(8)$ & $1(0)$ & $21(7)$ \\
\hline & & $\infty$ & $78(8)$ & $0(0)$ & $22(8)$ \\
\hline & unemployment & 1 & $14(10)$ & $5(6)$ & $81(15)$ \\
\hline & & 5 & $66(8)$ & $0(2)$ & 34 (13) \\
\hline & & $\infty$ & $90(5)$ & $2(2)$ & $8(4)$ \\
\hline
\end{tabular}


Table 3-(continued)

\begin{tabular}{|c|c|c|c|c|c|}
\hline \multicolumn{2}{|c|}{ Country/variable } & \multirow{2}{*}{$\frac{\text { Lag }}{1}$} & \multirow{2}{*}{$\begin{array}{c}\boldsymbol{\varepsilon}_{\boldsymbol{s}} \\
67(11)\end{array}$} & \multirow{2}{*}{$\frac{\varepsilon_{\boldsymbol{l}}}{3(3)}$} & \multirow{2}{*}{$\frac{\boldsymbol{\varepsilon}_{\boldsymbol{d}}}{30(11)}$} \\
\hline Netherlands & real wage & & & & \\
\hline & & 5 & $92(3)$ & $0(0)$ & $8(3)$ \\
\hline & & $\infty$ & $99(0)$ & $0(0)$ & $1(0)$ \\
\hline & output & 1 & $75(52)$ & $15(5)$ & $10(1)$ \\
\hline & & 5 & $84(4)$ & $10(4)$ & $6(0)$ \\
\hline & & $\infty$ & $72(4)$ & $8(2)$ & $20(3)$ \\
\hline & unemployment & 1 & $63(10)$ & $1(2)$ & $36(10)$ \\
\hline & & 5 & $60(9)$ & $10(1)$ & $20(8)$ \\
\hline & & $\infty$ & $56(92)$ & $15(0)$ & $29(7)$ \\
\hline \multirow[t]{9}{*}{ Norway } & real wage & 1 & $75(7)$ & $10(5)$ & $15(5)$ \\
\hline & & 5 & $69(8)$ & $20(7)$ & $11(3)$ \\
\hline & & $\infty$ & $96(2)$ & $1(0)$ & $3(1)$ \\
\hline & output & 1 & $74(9)$ & $9(10)$ & $17(3)$ \\
\hline & & 5 & $82(9)$ & $7(9)$ & $11(0)$ \\
\hline & & $\infty$ & $84(9)$ & $6(8)$ & $10(0)$ \\
\hline & unemployment & 1 & $22(14)$ & $5(6)$ & $73(14)$ \\
\hline & & 5 & $32(12)$ & $32(10)$ & $36(11)$ \\
\hline & & $\infty$ & $40(11)$ & $28(8)$ & $32(8)$ \\
\hline \multirow[t]{9}{*}{ Spain } & real wage & 1 & $65(7)$ & $10(5)$ & $25(5)$ \\
\hline & & 5 & $69(8)$ & $20(7)$ & $11(3)$ \\
\hline & & $\infty$ & $96(1)$ & $1(0)$ & $3(1)$ \\
\hline & output & 1 & $64(9)$ & $9(10)$ & $21(3)$ \\
\hline & & 5 & $72(9)$ & $7(9)$ & $21(1)$ \\
\hline & & $\infty$ & $84(9)$ & $6(10)$ & $10(0)$ \\
\hline & unemployment & 1 & $26(19)$ & $16(12)$ & $58(19)$ \\
\hline & & 5 & $39(10)$ & $13(9)$ & $38(11)$ \\
\hline & & $\infty$ & $45(3)$ & $12(0)$ & $53(7)$ \\
\hline \multirow[t]{9}{*}{ Sweden } & real wage & 1 & $40(17)$ & $28(14)$ & $32(13)$ \\
\hline & & 5 & $54(15)$ & $12(2)$ & $24(11)$ \\
\hline & & $\infty$ & $77(9)$ & $2(5)$ & $21(5)$ \\
\hline & output & 1 & $44(14)$ & $15(8)$ & $41(9)$ \\
\hline & & 5 & $39(11)$ & $21(13)$ & $40(8)$ \\
\hline & & $\infty$ & $89(8)$ & $3(4)$ & $9(3)$ \\
\hline & unemployment & 1 & $65(2)$ & $9(2)$ & $26(2)$ \\
\hline & & 5 & $85(2)$ & $4(2)$ & $11(1)$ \\
\hline & & $\infty$ & $80(3)$ & $3(1)$ & $17(1)$ \\
\hline \multirow[t]{9}{*}{ UK } & real wage & 1 & $78(1)$ & $1(0)$ & $21(3)$ \\
\hline & & 5 & $98(0)$ & $0(0)$ & $2(0)$ \\
\hline & & $\infty$ & $100(0)$ & $0(0)$ & $0(0)$ \\
\hline & output & 1 & $42(6)$ & $1(3)$ & $57(11)$ \\
\hline & & 5 & $46(3)$ & $16(6)$ & $38(9)$ \\
\hline & & $\infty$ & $73(2)$ & $18(5)$ & $9(4)$ \\
\hline & unemployment & 1 & $54(13)$ & $5(8)$ & $41(8)$ \\
\hline & & 5 & $63(13)$ & $7(6)$ & $30(7)$ \\
\hline & & $\infty$ & $64(11)$ & $7(5)$ & $29(6)$ \\
\hline
\end{tabular}


Table 3-(continued)

\begin{tabular}{|c|c|c|c|c|c|}
\hline \multicolumn{2}{|c|}{ Country/variable } & \multirow{2}{*}{$\begin{array}{c}\text { Lag } \\
1\end{array}$} & \multirow{2}{*}{$\begin{array}{c}\varepsilon_{s} \\
64(11)\end{array}$} & \multirow{2}{*}{$\frac{\boldsymbol{\varepsilon}_{\boldsymbol{l}}}{5(3)}$} & \multirow{2}{*}{$\frac{\boldsymbol{\varepsilon}_{\boldsymbol{d}}}{32(10)}$} \\
\hline US & real wage & & & & \\
\hline & & 5 & $89(3)$ & $1(0)$ & $10(3)$ \\
\hline & & $\infty$ & $98(0)$ & $0(0)$ & $2(0)$ \\
\hline & output & 1 & $58(7)$ & $3(2)$ & $39(3)$ \\
\hline & & 5 & $50(5)$ & $8(7)$ & $42(3)$ \\
\hline & & $\infty$ & $59(10)$ & $10(11)$ & $31(1)$ \\
\hline & unemployment & 1 & $30(6)$ & $4(11)$ & $66(12)$ \\
\hline & & 5 & $38(81)$ & $12(2)$ & $50(9)$ \\
\hline & & $\infty$ & $37(53)$ & $18(2)$ & $45(6)$ \\
\hline
\end{tabular}

Note: Standard errors are given in parentheses. They are calculated using Runkle's (1987) bootstrap method based on 1000 replications.

With regard to real output, productivity shocks dominate in the long-run in most countries. Demand shocks, in turn, generally play an important role in the shortrun, particularly in the UK and US.

From the view point of this paper the most interesting results are those related to the FEV decomposition of the unemployment rate. In the short-run, we find that the main contribution of unemployment fluctuation is largely driven by demand shocks in nine countries, by productivity shocks in five countries, and by labour supply shocks in Australia and Ireland. Productivity shocks dominate in the medium and long-run, although demand shocks still have a large contribution in Italy, Spain, and the US. Finally, labour supply shocks still play a large role in explaining the variability of Irish unemployment in the long-run.

\subsection{Measuring real wage rigidity}

A final exercise which could be undertaken within the present SVAR framework is to compute an index of real wage rigidity (RWR) for our sample of countries. This type of index has been popularized in the literature following the seminal work of Layard et al. (1991). In general, this index is computed as the reciprocal of the estimated response of real wages to the unemployment rate in a wage equation where, besides unemployment, a set of conditioning wage-push variables appear as regressors. According to the partial hysteresis version of the VAR, productivity shocks are the only shocks which have permanent effects on real wages; thus, a natural definition of RWR is given by

$$
\lim _{k \rightarrow \infty} \frac{\partial \sum_{0}^{\infty} \partial u_{t+k} / \partial \varepsilon_{s t}}{\partial(w-p)_{t+k} / \partial \varepsilon_{s t}}
$$

that is, the long-run relative effect of productivity shocks on unemployment and real wages. Notice that since no shock has permanent effect on unemployment, being an $\mathrm{I}(0)$ variable, the numerator is the accumulated effect of $\varepsilon_{s t}$ on $u_{t}$. 
Table 4 Real wage rigidity (RWR) indices.

\begin{tabular}{lccc}
\hline Country & RWR (LNJ, 1991) & RWR (3VAR) & RWR (2VAR) \\
\hline Australia & -1.10 & -3.90 & -3.20 \\
Austria & -0.11 & -1.66 & -1.55 \\
Belgium & -0.25 & -4.75 & -4.50 \\
Canada & -0.32 & -2.07 & -1.52 \\
Denmark & -0.58 & -4.07 & -3.82 \\
France & -0.23 & -2.51 & -3.49 \\
Germany & -0.63 & -1.29 & -1.74 \\
Ireland & -0.27 & -1.87 & -2.05 \\
Italy & -0.06 & -4.44 & -4.84 \\
Japan & -0.06 & -1.26 & -1.10 \\
Netherlands & -0.25 & -3.75 & -2.35 \\
Norway & -0.08 & -0.98 & -0.86 \\
Spain & -0.52 & -5.37 & -6.02 \\
Sweden & -0.08 & -2.16 & -1.80 \\
UK & -0.77 & -2.08 & -1.95 \\
US & -0.25 & -0.80 & -0.75 \\
\hline
\end{tabular}

Note: Column (1) offers the RWR index taken from Layard et al. (1991, Ch. 9, Table 2); Column (2) offers the RWR index computed as in (18) from a trivariate VAR (3VAR); Column (3) offers the RWR index computed as in (20) from a bivariate VAR (2VAR).

The second column in Table 4 presents our RWR index, while the first column offers the corresponding index as reported in LNJ (1991, Ch. 9, Table 2) for comparison. While the magnitudes differ, given that they are computed using different procedures, there is a relatively high degree of similarity between the rankings of countries stemming from both approaches. Real wage rigidity is low in Japan, USA, and the previous EFTA countries, with the exception of Denmark, and high in Australia, Belgium, Italy, and Spain. Noticeable differences appear in the cases of Belgium and Italy, and the UK which tend to have higher and lower rigidity, respectively, than what is reported by LNJ (1991).

Further, to check how robust our results are with regard to the chosen identification outline, we compute in what follows an alternative RWR index, using again the SVAR methodology but this time, based on a very simple labour market model which is closer in interpretation to the 'battle of mark-ups' model used in LNJ (1991) (see Castillo et al., 1998 for an application of this approach). The model is based upon a bivariate VAR formed by first-differenced log real wages and the unemployment rate and its basic structure is as follows. Assuming constant markup pricing, where the mark-up has been omitted for simplicity, prices are given by: $p-w=z_{p}$ where $z_{p}$ are price shocks assumed to follow an I(1) process. Wage determination negatively relates real wages to unemployment, as in the following equation: $w-p=-c\left(u-h u_{-1}\right)+z_{w}$ where $h<1$, i.e., a parameter capturing hysteresis and $z_{w}$ are wage-push shocks to the wage equation. Next, assume that shocks to the price-setting equation are interpreted as productivity shocks, as in the previous model, such that $z_{p}=-v_{s}-b \varepsilon_{s}$ where $\Delta v_{s}=\varepsilon_{s}$ and $\varepsilon_{s}$ is assumed i.i.d., 
again for simplicity. Notice that $v_{s}$ represents a permanent component and $\varepsilon_{s}$ is a transitory component as in the standard Beveridge-Nelson decomposition. Shocks to the wage equation include both permanent and transitory productivity shocks and (temporary i.i.d.) wage-push shocks $\left(\varepsilon_{w}\right)$, so that $z_{w}=v_{s}+b^{\prime} \varepsilon_{s}+\varepsilon_{w}$. Thus, solving for unemployment yields the following expression in terms of shocks

$$
u=h u_{-1}+(1 / c)\left[\varepsilon_{w}+\left(b^{\prime}-b\right) \varepsilon_{s}\right]
$$

whereas real wages are given by

$$
\Delta(w-p)=\varepsilon_{s}+b \Delta \varepsilon_{s}
$$

Thus, unemployment is $\mathrm{I}(0)$ and is affected by transitory wage shocks and by productivity shocks if $b \neq b^{\prime}$. Real wages, in turn, are I(1) and are only affected by productivity shocks, given the CRS production function underlying the pricesetting equation. The long-run multiplier matrix of (19)-(20) in a compact form is given by

$$
\left(\begin{array}{c}
\Delta(w-p) \\
u
\end{array}\right)=\left(\begin{array}{cc}
c_{11}(1) & 0 \\
c_{21}(1) & c_{22}(1)
\end{array}\right)\left(\begin{array}{c}
\varepsilon_{s} \\
\varepsilon_{w}
\end{array}\right)
$$

where $c_{11}(1)=1, c_{21}(1)=\left(b^{\prime}-b\right) / c(1-h)$, and $c_{22}(1)=1 / c(1-h)$.

Therefore, following the original interpretation in LNJ, whereby RWR reflects the response of unemployment to a shock in the wage-push factors, the previous model suggests a simple measure based upon an estimate of $c_{22}(1)$. The RWR index is larger the smaller is $c$ and the larger is $h$, i.e., the smaller is the response of equation real wages to unemployment and the larger is the degree of hysteresis. In view of eq. (20), the proposed index can be easily computed by means of the lower triangular Cholesky decomposition of the long-run covariance matrix of the bivariate VAR formed by $[\Delta(w-p), u]$, which yields an estimate of the long-run response of $u$ with respect to $\varepsilon_{w}$. The results are reported in the third column of Table 4 and they tend to confirm the results previously found for the trivariate VAR, with the exceptions of France and The Netherlands which now show higher and lower RWR, respectively, than what was found with the LNJ index.

\section{Conclusions}

In this paper we have presented empirical evidence on the dynamic responses of real wages, real output and the unemployment rate to aggregate demand, productivity, and labour supply shocks in a sample of sixteen OECD economies over the period 1950-96. To this end, we have exploied the identification restrictions stemming from a simple insider-outsider model of the labour market which allows us to obtain structural shocks with the previous interpretation through a recursive set of long-run restrictions on the matrix of long-run multipliers of the system. Furthermore, as a byproduct of the analysis, we are able to evaluate the cyclical properties of real wages in response to a demand shock and to construct simple indices of real wage rigidity which compare well with other indices available in the literature. 
Our main results can be summarised as follows. First, we find that in most countries the identification scheme based on unemployment being persistent but stationary yields more reasonable results than that based on full-hysteresis whereby unemployment is considered to be an I(1) variable. Thus, our analysis offers further support to those approaches which test for an extreme degree of persistence in unemployment, i.e., a unit root, in a multivariate framework instead of in a simple univariate one where persistence is systematically overstated.

Secondly, we find that, in most cases, unemployment fluctuations are dominated by aggregate demand shocks in the short-run and by labour supply and productivity shocks at lower frequencies. However, in some highly sclerotic economies like Italy and Spain, demand shocks seem important in explaining the variability of unemployment in the medium- and long-run. This result also holds in the US, in agreement with previous findings by Blanchard and Quah (1989) and Gamber and Joutz (1993). Likewise, in other countries, like Ireland, where population changes have been sizeable, labour supply shocks dominate at all frequencies. Thirdly, as regards the cyclical behaviour of real wages, we find in all countries, except in the US, real wages react in a countercyclical way to aggregate demand shocks, supporting sticky-wage theories of the business cycle.

Lastly, regarding the real wage rigidity indices constructed here under the SVAR methodology, we find that they support previous rankings of countries in the literature, based upon alternative methodologies. Noticeable exceptions are Belgium, Italy, and the UK. The first two countries appear to have more rigid labour markets than was previously found, while the latter seems to have lower rigidity.

\section{Acknowledgements}

We are grateful to Anton Braun, Jeff Campbell, Jonas Fisher, Jordi Galí, an anonymous referee, and participants at the conference 'Unemployment Persistence and the Long Run: Re-evaluating the Natural Rate', Vigo, December 1997, for helpful comments. All remaining errors are ours.

\section{References}

Bean, C. (1992). 'Identifying the Causes of British Unemployment', Working Paper No. 276, CEP, London School of Economics, London.

Blanchard, O. and Summers, L. (1986). 'Hysteresis and the European Unemployment Problem', NBER Macroeconomics Annual 1986, 15-78.

Blanchard, O. and Quah, D. (1989). 'The Dynamic Effects of Aggregate Demand and Aggregate Supply Disturbances', American Economic Review, 79, 655-73.

Blanchard, O. (1991). 'Wage Bargaining and Unemployment Persistence', Journal of Money, Credit and Banking, 23, 277-92. 
Cåstillo, S., Dolado, J. and Jimeno, J.F. (1998). 'A Tale of Two Neighbour Economics: Labour Market Dynamics in Portugal and Spain’, Discussion Paper, No. 1954, CEPR, London.

Clarida, R. and Galí, J. (1994). 'Sources of Real Exchange-rate Fluctuations: How Important are Nominal Shocks?' Carnegie-Rochester Conference Series on Public Policy, 41, 1-56.

Dolado, J. and López-Salido, J.D. (1996). 'Histeresis y Fluctuaciones Económicas: España, 1970-92', Moneda y Crédito, 201, 117-55.

Dolado, J. and Jimeno, J.F. (1997). 'The Causes of Spanish Unemployment: A Structural VAR Approach', European Economic Review, 41, 1281-307.

Fischer, S. (1977). 'Long Term Contracts, Rational Expectations, and the Optimal Money Supply Rule', Journal of Political Economy, 85, 163-90.

Galí, J. (1996). 'Technology, Employment and the Business Cycle: Do Technology Shocks Explain Aggregate Fluctuations', Discussion Paper No. 1499, CEPR, London.

Gamber, E. and Joutz, F. (1993). 'The Dynamic Effects of Aggregate Demand and Supply Disturbances: Comment', American Economic Review, Papers and Proceedings, 83, 1387-93.

Johansen, S. (1995), Likelihood-Based Inference in Cointegrated Vector Autoregessive Models, Oxford University Press, Oxford.

Layard, R., Nickell, S. and Jacman, R. (1991). Unemployment: Macroeconomic Performances and the Labour Market, Oxford University Press, Oxford.

Lindbeck, A. and Snower, D. (1988). The Insider-Outsider Theory of Employment and Unemployment, MIT Press, Boston, MA.

Manning, A. (1993). 'Wage Bargaining and the Phillips Curve: The Identification and Specification of Aggregate Wage Equations', Economic Journal, 103, 98-118.

Nickell, S. (1987). 'Why is the Wage Inflation in Britain So High?', Oxford Bulletin of Economics and Statistics, 49, 103-28.

Osterwald-Lenum, M. (1992). 'A Note with Quantiles of the Asymptotic Distribution of the Maximum Likelihood Cointegration Rank Test Statistics: Four Cases', Oxford Bulletin of Economics and Statistics, 54, 461-73.

Runkle, D. (1987). 'Vector Autoregressions and Reality', Journal of Business and Economic Statistics, 5, 435-42. 